\title{
Hubungan Karakteristik dan Tekanan Sosial dengan Perilaku Berisiko Penularan HIV/AIDS
}

\author{
Sri Mindayani ${ }^{\mathrm{a}^{*}}$, Hilda Hidayat ${ }^{\mathrm{b}}$ \\ Fakultas Kesehatan Masyarakat, Universitas Baiturrahmah, Padang 25586, Indonesia \\ asrimindayani@ fkm.unbrah.ac.id*, bhildahidayat15@gmail.com \\ * corresponding author
}

ARTICLE INFO

Keywords

Characteristic

Social Pressure

Behavior

HIV/AIDS

\begin{abstract}
HIV / AIDS in Indonesia was concentrated in certain population groups (key populations) who have a high risk of HIV transmission related to their behavior, one of which is loading worker. This study aims to determine the relationship of characteristics and social pressures with risk behaviors of HIV / AIDS transmission in loading workers in Port of Padang City. This type of research was analytic with cross sectional design. This research was conducted from January - April 2019 at the Port of Padang City. The study population numbered 834 people and a sample of 90 people. Sampling was done by cluster sampling technique. Primary data collection is done by interview using a questionnaire. Data analysis includes univariate analysis and bivariate analysis. The results showed no relationship between age, education, and ethnicity with HIV/AIDS risk behavior in loading workers. There was a relationship between social pressure and HIV/AIDS risk behavior in loading workers. It is recommended to Koperbam to provide information routinely on HIV / AIDS risk behavior in loading workers. It is also recommended that Koperbam cooperate with the local health center to carry out an HIV check.
\end{abstract}

\section{Pendahuluan}

Indonesia merupakan negara dengan jumlah kasus HIV paling banyak di Asia Tenggara yaitu diperkirakan 48.000 kasus. Di ASIA, Indonesia menempati urutan ketiga terbesar dalam kasus HIV/AIDS [1]. Jumlah kasus HIV di Indonesia pada saat ini terus mengalami peningkatan dari tahun ke tahun. Pada tahun 2014 terdapat 32.711 kasus, tahun 2015 terdapat 30.395 kasus dan pada tahun 2016 terdapat 41.250 kasus.

HIV AIDS di Indonesia terkonsentrasi pada kelompok-kelompok populasi tertentu (populasi kunci) yang memiliki risiko tinggi penularan HIV terkait perilaku mereka, salah satunya yaitu Tenaga Kerja Bongkat Muat (TKBM). TKBM merupakan pria yang potensial menjadi pelanggan WPS [2]. Berdasarkan STBP tahun 2015, jumlah kasus HIV/AIDS pada populasi TKBM tahun 2007 yaitu $0,8 \%$, tahun 2011 menurun menjadi $0,7 \%$ dan tahun 2015 meningkat menjadi $0,82 \%$ [3].

Data dari Dinkes Kota Padang tahun 2017, menunjukkan jumlah kasus HIV sebanyak 300 orang, dimana paling banyak pada laki-laki yaitu 297 orang dan pada perempuan 71 orang [4]. Hasil survey awal di puskesmas kawasan pelabuhan Kota Padang, menunjukkan trend peningkatan kasus HIV/AIDS. Pada tahun 2014 terdapat 15 kasus, tahun 2015 terdapat 21 kasus dan tahun 2016 terdapat 24 kasus.

Hasil wawancara dengan Koperasi Tenaga Kerja Bongkat Muat (KOPERBAM) Teluk Bayur, diketahui bahwa beberapa orang TKBM memiliki perilaku berisiko tertular HIV/AIDS, 
dimana adanya kegiatan pembelian seks oleh TKBM. Hal ini dikarenakan lokasi pelabuhan dekat dengan lokasi prostitusi yang ada di Kota Padang. Walalupun lokasi prostitusi bukan berupa lokalisasi, akan tetapi pada lokasi ini selalu terdapat aktivitas prostitusi. Jarak yang dekat antara pelabuhan dengan lokasi prostitusi, menyebabkan TKBM memiliki akses yang mudah untuk melakukan kegiatan berisiko tertular HIV/AIDS.Penelitian ini bertujuan untuk mengetahui hubungan karakteristik dan tekanan sosial dengan perilaku berisiko penularan HIV/AIDS pada Tenaga Kerja Bongkar Muat di Kota Padang.

\section{Metode}

Jenis penelitian ini adalah analitik dengan desain cross sectional. Penelitian ini dilakukan dari bulan Januari-April 2019 di Pelabuhan Kota Padang. Populasi penelitian berjumlah 834 orang dan sampel sebanyak 90 orang. Pengambilan sampel dilakukan dengan teknik cluster sampling. Pengumpulan data primer dilakukan dengan teknik wawancara menggunakan kuesioner. Analisis data meliputi analisis univariat, analisis bivariat untuk menguji ada tidaknya hubungan variabel independen dengan variabel dependen menggunakan uji chi square pada tingkat kepercayaaan 95\% $(\mathrm{p}<0,05)$. Variabel dependen dalam penelitian ini yaitu perilaku pencegahan penularan HIV/AIDS dan variabel independen yaitu umur, pendidikan, suku, dan tekanan sosial.

\section{Hasil dan Diskusi}

\section{Analisis Univariat}

a. Umur ini:

Umur TKBM di Pelabuhan Kota Padang tahun 2019 dapat dilihat pada tabel 1. di bawah

Tabel 1.Distribusi Frekuensi TKBM Berdasarkan Umur

\begin{tabular}{cccc}
\hline No & Umur & f & \% \\
\hline 1 & $<25$ tahun & 3 & 3,3 \\
2 & $\geq 25$ tahun & 87 & 96,7 \\
& Total & $\mathbf{1 0 0}$ & $\mathbf{1 0 0}$ \\
\hline
\end{tabular}

Berdasarkan tabel 1. di atas dapat diketahui bahwa sebagian besar umur TKBM berada pada kategori umur $\geq 25$ tahun yaitu sebanyak 96,7\%.Penelitian Kambu, dkk menunjukkan bahwa umur merupakan faktor yang mempengaruhi pencegahan penularan HIV/AIDS. Pada penelitian ini, didapatkan perbedaan proporsi yang bermakna antara ODHA umur muda dan tua. Data ini dapat menjelaskan bahwa infeksi HIV ternyata lebih banyak terjadi pada umur muda ketimbang umur tua. Hal ini disebabkan karena umur muda lebih mungkin banyak melakukan perilaku seks tidak aman yang berisiko terhadap penularan HIV [5].

\section{b. Pendidikan}

Masing-masing TKBM memiliki tingkat pendidikan yang berbeda. Gambaran pendidikan TKBM di Pelabuhan Kota Padang dapat dilihat pada tabel 2 berikut:

Tabel 2.Distribusi Frekuensi TKBM Berdasarkan Pendidikan

\begin{tabular}{cccc}
\hline No & Pendidikan Terakhir & f & \% \\
\hline 1 & Rendah (SD, SMP) & 40 & 44,4 \\
2 & Tinggi (SMA, D3, S1) & 50 & 55,6 \\
\hline & Total & $\mathbf{9 0}$ & $\mathbf{1 0 0}$ \\
\hline
\end{tabular}

Berdasarkan tabel 2. di atas dapat diketahui bahwa sebagian besar TKBM memiliki pendidikan tinggi yaitu sebanyak 50 orang $(55,6 \%)$.

Menurut hasil penelitian Majelantle bahwa semakin rendah usia seseorang $(\mathrm{OR}=0,689)$ yang berada pada tingkat sekolah dasar $(\mathrm{OR}=0,235)$ cenderung memiliki pengetahuan yang benar tentang hubungan antara HIV/ AIDS dan tentang penularan HIV dan pencegahan daripada mereka yang berusia lebih tua [6].

\section{c. Suku}

Masing-masing TKBM memiliki suku yang berbeda. Gambaran suku TKBM di pelabuhan 
Kota Padang dapat dilihat pada tabel 3 di bawah ini :

Tabel 3.Distribusi Frekuensi TKBM Berdasarkan Suku

\begin{tabular}{clcc}
\hline No & Suku & f & \% \\
\hline 1 & Minang & 65 & 72,2 \\
2 & Jawa & 3 & 3,3 \\
3 & Melayu & 12 & 13,3 \\
4 & Nias & 10 & 11,1 \\
\hline & Total & $\mathbf{9 0}$ & $\mathbf{1 0 0}$ \\
\hline
\end{tabular}

Berdasarkan tabel 3. di atas dapat diketahui bahwa lebih dari separoh $(72,2 \%)$ TKBM di Pelabuhan Kota Padang merupakan Suku Minang. Penelitian yang dilakukan oleh peneliti pada tahun 2018 pada warga binaan pemasyarakatan (WBP) di Lapas Kelas IIA Padang juga menunjukkan bahwa suku paling banyak adalah Suku Minang [7].

Pekerja TKBM pada umumnya Suku Minang dikarenakan letak demografi pelabuhan yang berada di wilayah Sumatera Barat. Pada umumnya, penduduk Sumatera Barat bersuku Minang dan hanya sebagian kecil di luar suku Minang.

Hasil penelitian yang dilakukan oleh Hermanus menunjukkan faktor perilaku masyarakat Papua seperti perilaku seks bebas, merosotnya nilai agama dan kebiasaan budaya negatif di Biak mempunyai risiko terhadap terjangkitnya penyakit HIV-AIDS [8].

\section{d. Tekanan Sosial}

Dari hasil pengambilan data primer yang dilakukan terhadap 90 orang TKBM, didapatkan data sebagai berikut:

Tabel 4.Distribusi Frekuensi Tekanan Sosial Pada TKBM

\begin{tabular}{cccc}
\hline No & Tekanan Sosial & f & \% \\
\hline 1 & Tidak Ada Tekanan & 56 & 62,2 \\
2 & Ada Tekanan & 34 & 37,8 \\
& Total & $\mathbf{9 0}$ & $\mathbf{1 0 0}$ \\
\hline
\end{tabular}

Berdasarkan tabel 4. dapat diketahui bahwa sebanyak 62,2\% TKBM di Pelabuhan Kota Padnag tidak mendapatkan tekanan sosial dalam perilaku berisiko penularan HIV/AIDS.

Berikut ini adalah gambaran jawaban TKBM berdasarkan tekanan sosial sebagaimana disajikan pada tabel 5 sebagai berikut:

Tabel 5.Distribusi Frekuensi Jawaban Kuesioner Tekanan Sosial Pada TKBM di Pelabuhan Kota Padang

\begin{tabular}{clcccc}
\hline \multirow{2}{*}{ No } & \multicolumn{1}{c}{ Pertanyaan } & \multicolumn{2}{c}{ Ya } & \multicolumn{2}{c}{ Tidak } \\
\cline { 3 - 6 } & & f & \% & f & \% \\
\hline 1. & Teman yang menggunakan narkotika & 22 & 24,4 & 68 & 75,6 \\
2. & Teman mengajak menggunakan narkotika & 9 & 10 & 81 & 90 \\
3. & Teman melakukan hubungan seksual secara bebas & 18 & 20 & 72 & 80 \\
4. & Teman mengajak hubungan seksual secara bebas & 17 & 18,9 & 73 & 81,1 \\
5. & Teman melakukan hubungan seksual sesama jenis & 3 & 3,3 & 87 & 96,7 \\
6 & Teman mengajak hubungan seksual sesama jenis & 1 & 1,1 & 89 & 98,9 \\
\hline
\end{tabular}


Berdasarkan tabel 5 dapat diketahui bahwa sebanyak 24,4\% TKBM di Pelabuhan Kota Padanga dalam setahun terakhir memiliki teman yang menggunakan narkotika, sebanyak $20 \%$ TKBM memiliki teman yang mempunyai kebiasaan berhubungan seksual secara bebas, dan 18,9\% TKBM pernah diajak oleh teman untuk melakukan hubungan seksul secara bebas.

Hasil penelitian ini menunjukkan bahwa tekanan sosial yang diberikan oleh orang terdekat TKBM tidak begitu besar. Penelitian ini hampir sama dengan penelitian yang dilakukan oleh peneliti pada tahun 2018 pada WBP di Lapas Kelas IIA Padang. Sebagian besar WBP memiliki teman yang mengonsumsi narkoba (58\%) dan mengajak untuk mengonsumsi narkoba (50\%) (7). Penelitian ini menunjukkan bahwa kelompok WBP juga mendapatkan tekanan sosial dari teman mereka dalam perilaku berisiko HIV/AIDS.

\section{e. Perilaku Berisiko HIV/AIDS}

Gambaran perilaku berisiko HIV/AIDS pada TKBM di Pelabuhan Kota Padang dapat dilihat pada tabel 6:

Tabel 6.Distribusi Frekuensi Perilaku Berisiko HIV/AIDS Pada TKBM

\begin{tabular}{|c|c|c|c|}
\hline No & Perilaku Berisiko & f & $\%$ \\
\hline 1 & Tidak Berisiko & 56 & 62,2 \\
\hline 2 & Berisiko & 34 & 37,8 \\
\hline & Total & 90 & 100 \\
\hline
\end{tabular}

Berdasarkan tabel 6. dapat diketahui bahwa sebanyak 62,2\% TKBM di Pelabuhan Kota Padang tidak memiliki perilaku tidak berisiko dalam penularan HIV/AIDS.

Berikut ini adalah gambaran jawaban TKBM berdasarkan perilaku berisiko HIV/AIDS sebagaimana disajikan pada tabel 7 sebagai berikut:

Tabel 7. Distribusi Frekuensi Jawaban Kuesioner Perilaku Berisiko HIV/AIDS Pada TKBM di Pelabuhan Kota Padang

\begin{tabular}{clcccc}
\hline \multirow{2}{*}{ No } & \multicolumn{1}{c}{ Pertanyaan } & \multicolumn{2}{c}{ Ya } & \multicolumn{2}{c}{ Tidak } \\
\cline { 3 - 6 } & & f & \% & f & \% \\
\hline 1. & Penggunaan narkotika & 1 & 1,1 & 89 & 98,9 \\
2. & Menyuntikkan narkotika secara bersama-sama & 1 & 1,1 & 89 & 98,9 \\
3. & Melakukan hubungan seksual dengan orang yang berbeda & 19 & 21,1 & 71 & 78,9 \\
& Penggunaan kondom saat berhubungan seksual & 24 & 26,7 & 66 & 73,3 \\
4. & Selalu menggunakan kondom saat berhubungan seksual & 15 & 16,7 & 75 & 83,3 \\
6 & Pernah dipaksa melakukan hubungan seksual dengan orang lain & 10 & 11,1 & 80 & 88,9 \\
7 & Melakukan hubungan seksual melalui anal & 6 & 6,7 & 84 & 93,3 \\
8 & Melakukan hubungan seksual melalui oral & 6 & 6,7 & 84 & 93,3 \\
9 & Membeli orang untuk melakukan hubungan seksual & 12 & 13,3 & 78 & 86,7 \\
10 & Dibayar orang untuk melakukan hubungan seksual dengan & 9 & 10 & 81 & 90 \\
& responden & 18 & 20 & 72 & 80 \\
\hline 11 & Memiliki tato & 3 & 3,3 & 87 & 96,7 \\
\hline 12 & Pernah mentato dengan menggunakan jarum yang sama & 7 & 7,8 & 83 & 92,2 \\
\hline & Berbagi alat cukur & & & & \\
\hline
\end{tabular}

Berdasarkan tabel 7. diketahui pada umumnya perilaku pekerja tidak berisiko dalam penularan HIV/AIDS. Akan tetapi, masih terdapat beberapa pekerja yang memili perilaku berisiko, seperti tidak menggunakan kondom di saat berhubungan seksual $(73,3 \%)$ dan tidak selalu menggunakan kondom saat berhubungan seksual (83,3\%).

Penelitian ini sejalan dengann penelitian Laksana dan Lestari yang menunjukkan bahwa laki-laki heteroseksual maupun homoseksual memiliki kecenderungan tidak menggunakan kondom pada saat melakukan hubungan seksual [9].

\section{Analisis Bivariat}

\section{a. Hubungan Umur dengan Perilaku Pencegahan HIV/AIDS}

Hasil penelitian tentang hubungan umur dengan perilaku berisiko penularan HIV/AIDS pada TKBM di Pelabuhan Kota Padang, didapatkan data di bawah ini: 
Tabel 8. Hubungan Umur dengan Perilaku Berisiko Penularan HIV/AIDS pada TKBM di Pelabuhan Kota Padang Tahun 2019

\begin{tabular}{|c|c|c|c|c|c|c|c|c|}
\hline \multirow{3}{*}{ No } & \multirow{3}{*}{ Umur } & \multicolumn{4}{|c|}{$\begin{array}{c}\text { Perilaku Berisiko Penularan } \\
\text { HIV/AIDS }\end{array}$} & \multicolumn{2}{|c|}{ Jumlah } & \multirow[t]{3}{*}{ P Value } \\
\hline & & \multicolumn{2}{|c|}{ Tidak Berisiko } & \multicolumn{2}{|c|}{ Berisiko } & & & \\
\hline & & $\mathbf{F}$ & $\%$ & $\mathbf{F}$ & $\%$ & $\mathbf{F}$ & $\%$ & \\
\hline 1 & Tidak Berisiko & 26 & 60,5 & 17 & 39,5 & 43 & 100 & \\
\hline 2 & Berisiko & 30 & 63,8 & 17 & 36,2 & 47 & 100 & 0,742 \\
\hline & Jumlah & 56 & 62,2 & 34 & 37,8 & 90 & 100 & \\
\hline
\end{tabular}

Berdasarkan tabel 8. dapat diketahui bahwa responden yang pada umur tidak berisiko $(60,5 \%)$ lebih sedikit memiliki perilaku pencegahan yang tidak berisiko dalam penularan HIV/AIDS dibandingkan dengan responden yang berada pada kategori umur berisiko $(63,8 \%)$. Hasil uji statistik diperoleh nilai $\mathrm{P}$ Value 0,742 yang berarti tidak terdapat hubungan yang bermakna antara umur dengan perilaku pencegahan penularan HIV/AIDS. Penelitian ini menunjukkan bahwa umur WBP cenderung tidak menentukan perilaku dalam mencegah penularan HIV/AIDS.

Penelitian ini sejalan dengan penelitian Mindayani dan Hidayat yang menunjukkan bahwa umur tidak memiliki hubungan dengan perilaku pencegahan penularan HIV/AIDS di Lapas Kelas IIA Padang Tahun 2018[7].

Penelitian ini juga sejalan dengan penelitian Barus, dimana umur tidak memiliki hubungan dengan perilaku penggunaan konsom pada PSK di Puskesmas Bandar Baru tahun 2015 [10].

Penelitian ini tidak sesuai dengan penelitian Purba, dkk yang menunjukkan adanya hubungan antara umur dengan perilaku tindakan berisiko HIV/AIDS di Lapas Kelas IIB Lubuk Pakam. Pada penelitian ini, temuan Purba, dkk menunjukkan bahwa semakin muda umur seseorang maka kecenderungan seseorang berperilaku berisiko dalam penularan HIV/AIDS semakin tinggi [11].

Asumsi peneliti umur berkaitan dengan pengalaman yang dialami seseorang selama hidupnya. Pada umumnya, semakin lama seseorang hidup maka akan semakin banyak pengalamanpengalaman tentang berbagai aspek kehidupan. Hal ini juga berkaitan dengan pengalaman seseorang dalam perilaku pencegahan HIV/AIDS. Semakin tua seseorang, maka akan semakin banyak pengalaman seseorang dalam mendapatkan informasi tentang HIV/AIDS. Akan tetapi, karena kehidupan TKBM berasal dari berbagai latar belakang, sehingga pengalaman dan umur tidak mempengaruhi perilaku TKBM dalam pencegahan penularan HIV/AIDS.

\section{Pembahasan}

Berada di lingkungan yang mengajak dan mempengaruhi TKBM untuk melakukan hubungan seks bebas, telah menyebabkan 21,1\% TKBM pernah melakukan hubungan seksual secara bebas. Dengan adanya perilaku seksual secara bebas pada TKBM, maka secara tidak langsung akan mempengaruhi perilaku berisiko dalam penularan HIV/AIDS. Sehingga, untuk meminimalisir perilaku berisiko HIV/AIDS pada TBM yang disebabkan oleh adanya tekanan sosial, perlu adanya perhatian dari Koperbam berupa pemberian informasi secara rutin dalam perilaku berisiko HIV/AIDS pada TKBM. Selain itu, disarankan kepada Koperbam agar bekerjasama dengan puskesmas setempat untuk melaksanakan pemeriksaan HIV, dikarenakan adanya perilaku seksual bebas pada TKBM.

\section{Kesimpulan}

Berdasarkan hasil penelitian bahwa tidak adanya hubungan antara umur dengan perilaku berisiko HIV/AIDS pada TKBM di Pelabuhan Kota Padang tahun 2019. Tidak adanya hubungan antara pendidikan dengan perilaku berisiko HIV/AIDS pada TKBM di Pelabuhan Kota Padang tahun 2019. Tidak adanya hubungan antara suku dengan perilaku berisiko HIV/AIDS pada TKBM di Pelabuhan Kota Padang tahun 2019. Ada hubungan antara tekanan sosial dengan perilaku berisiko HIV/AIDS pada TKBM di Pelabuhan Kota Padang tahun 2019. 


\section{Referensi}

[1] NAIDS. UNAIDS Data 2017. Reference [Internet]. 2017;246. Available from: http://www.unaids.org

[2] Kementerian Kesehatan. Analisis Kecenderungan Perilaku Berisiko Terhadap HIV Di Indonesia 2007. 2009;

[3] Kementerian Kesehatan. Survei Terpadu Biologis dan Perilaku 2015. 2015;

[4] Dinas Kesehatan Kota Padang. Laporan Tahunan Dinas Kesehatan Kota PadangTahun 2017. 2018;

[5] Kambu Y, Waluyo A, Kuntarti K. Umur Orang dengan HIV AIDS (ODHA) Berhubungan dengan Tindakan Pencegahan Penularan HIV. J Keperawatan Indones. 2016;19(3):200-207.

[6] Majelantle RG, Keetile M BK, P N. Knowledge, Opinions and attitudes towards HIV and AIDS among Youth in Botswana. J Glob Econ. 2014;2(1):3-7.

[7] Mindayani S, Hidayat H. Hubungan Karakteristik Dan Tekanan Sosial Dengan Perilaku Pencegahan Penularan Hiv/Aids Pada Wbp Di Lapas Kelas Iia Padang. J Ris Hesti Medan Akper Kesdam I/BB Medan [Internet]. 2018;3(2):38-47. Available from: https://jurnal.kesdammedan.ac.id/index.php/jurhesti/article/view/42

[8] Hermanus A, Zeth M, Penyakit R, Asdie AH, Mukti AG, Mansoden J, et al. Perilaku dan Risiko Penyakit HIV-AIDS di Masyarakat Papua Studi Pengembangan Model Lokal Kebijakan HIV-AIDS. J Manaj Pelayanan Kesehat. 2010;13(04):206-19.

[9] Laksana, ASD , Lestar D. Faktor-Faktor Risiko Penularan HIV/AIDS pada Laki-Laki dengan Orientasi Seks Heteroseksual dan Homoseksual di Purwokerto. Manda Heal. 2010;40(2):113-23.

[10] Barus DJ. Hubungan Komponen Health Belief Model (HBM) Dengan Penggunaan Kondom Pada Pekerja Seks Komersil (PSK) Di Wilayah Kerja Puskesmas Bandar Baru Tahun 2015. J Mutiara Kesehat Masy. 2017;1(2):9-15.

[11] Purba, E.K.A, Yustina, I F. Pengaruh Karakteristik Penghuni Lapas terhadap Tindakan Berisiko HIV-AIDS di Lapas Kelas IIB Lubuk Pakam. 2009; Available from: media.neliti.com

[12] Seniorita D. Pengetahuan dan Sikap Remaja Putri dalam Upaya Deteksi Dini Kanker Payudara Di SMA Yaspend Paba Tahun 2017 T. 2017;2(2):93-104.

[13] Isniati. Kesehatan Modern Dengan Nuansa Budaya. J Kesehat Masy. 2012;7(1):42.

[14] Hardani R. Hubungan Persepsi Siswa Dikmata TNI Al dengan Perilaku Beresiko Penularan HIV/AIDS pada Prajurit Tni Al Di Kobangdikal Tahun 2013. 2013;01(01):53-65. 